\title{
Phenomenal Experiences, First-Person Methods, and the Artificiality of Experimental Data
}

Uljana Feest, talk for PSA 2012

(Symposium: Introspective Evidence in the Scientific Study of Perception)

This paper argues that whereas philosophical discussions of first-person methods often turn on the veridicality of first-person reports, more attention should be paid to the experimental circumstances under which the reports are generated, and to the purposes of designing such experiments. After pointing to the 'constructedness' of first-person reports in the science of perception, I raise questions about the criteria by which to judge whether the reports illuminate something about the nature of perception. I illustrate this point with a historical debate between Gestalt psychologist and atomists, both of whom used first-person methods to investigate perception.

\section{Introduction: Introspection and First-Person Methods}

In the course of recent interest in the methods of consciousness studies and cognitive neuroscience, quite a few arguments have been made to the effect that introspective reports are a valuable - and indeed necessary - source of data. While this may seem obvious to anybody working in consciousness studies, or even in the more traditional field of psychophysics, it is not uncontroversial. One reason for this is that the terminology of introspection is used fairly loosely, and it is not always clear that scholars arguing about the value of introspection all have in mind the same thing. These terminological differences can have their roots in both philosophical and scientific differences (or some combination of the two). For example, there are several competing philosophical accounts of introspection (Robbins 2006). In turn, scientific accounts of introspection tend to make fairly substantial assumptions about the ways in which introspection fits in with various other cognitive functions and capacities, such as attention, control, metacognition, and the like (e.g., Schooler 2002). Given these different approaches and accounts, it may seem that in order to engage in fruitful discussions about the epistemic value of introspective data, one will need to get clear on what one means by "introspection," and that this will require a substantive engagement with (and evaluation of) the philosophical and theoretical presuppositions that enter into such debates (I have argued this in Feest 2012).

In this paper, I will take a different approach, however: Rather than venturing into a debate over the nature of introspection, I shall avoid this terminology (though of course much of what I say touches on topics that are debated in the introspection literature). Instead, I will refer only to "first-person methods". I shall assume that first-person methods allow for the production of first-person data, i.e., the kinds of data one gets as a result of asking subjects to report some aspects of what they take to be their own mental content. This approach allows me to remain agnostic with respect to the nature of introspection since it does not commit me to the idea that first-person data are always mediated by introspective processes (whatever those may be). Nor does it commit me to the idea that they are always mediated by the same kinds of processes (introspective or not).

Having thus slightly broadened the focus in one respect, I also intend to narrow it in another respect, looking at the use of first-person methods in the study perception, specifically on the use of first-person reports about phenomenal experience in the study of perception. Existing debates often focus on the question of whether the data generated by first-person methods qualify as properly scientific data, in particular turning on questions about the veridicality of first-person reports. Drawing on experiments and methodological reflections of Gestalt psychological 
accounts of perception, I will argue that veridicality does not seem to be of great concern. Instead I will draw attention to the artificiality or 'constructedness' of the experiences reported in this research. The thesis of this paper is that while this constructedness does not make first-person reports of phenomenal experiences problematic per se, it does raise intriguing epistemological questions about their relevance to questions about the nature of perception.

\section{First-Person Methods and Phenomenal Experience: Some Background}

There are different kinds of things a person can report about themselves: They can report their own phenomenal subjective experience; they can report non-phenomenal mental states (e.g., intentions or preferences), or, even more broadly, personality traits (see Robbins 2006, who refers to these as primary, secondary and tertiary introspection). In this paper, I will exclusively focus on first-order questions, i.e., first-person reports of phenomenal mental states. One field of research where this question is obviously pertinent is psychophysics, an area of experimental psychology that aims at correlating physical stimuli and various features of subjective experience in order to learn something about human perception. Obviously, if a science of perception requires data about subjective phenomenal experience, first-person reports are going to be necessary. In other words, we have to work with first-person reports as evidence for subjective experiences. ${ }^{1}$

Much of the philosophical literature about introspection has focused on the question of whether first-person data can be scientific, and how it can be determined that such reports are veridical, given the subjectivity both of their object (phenomenal experience) and of their source (the experiencing subject). In response to these questions, Piccinini (2009) gives a two-fold answer: First, he points out that the scientific data in question are not the introspectively accessible experiences as such, but the public reports of such experiences. Secondly, he argues, the veridicality of these reports can be validiated by intersubjective means. While I am in full agreement with the first point, I am less confident about the second point (see also Feest 2012). However, it seems to me that at least in the field of psychophysics scientists do not seem to be overly worried about the veridicality of the reports in the first place. But if we want to pursue a type of philosophy of science that is sensitive to real scientific concerns, the question is what they $d o$ worry about? I argue that they worry about whether a given experiential report elicited in an experiment licenses the inferences the experimenter hopes to make.

To get a better grip on this worry, we need to look more closely at the specific purposes to which scientists put first-person reports. Specifically, if we are interested in the status of firstperson reports about phenomenal experience in a given investigative context, we should be clear (1) what are the experimental methods scientists use to determine phenomenal experience, (2) what do scientists hope to find out about perception by doing so, and (3) how can it be determined that the purpose has been met successfully in a given experiment? With these questions, I hope to get away from general philosophical puzzles about first-person methods, asking instead what are criteria for determining their scientific utility in specific contexts.

In the following section, we begin with a brief discussion of the first two questions. This discussion takes as a point of departure a historical debate between two early $20^{\text {th }}$ century schools in the experimental study of perception (Gestalt psychologists and atomists), both of whom used first-person reports of phenomenal experience as their empirical data. I will show that they

\footnotetext{
${ }^{1}$ Notice, though, that this assumption relies on two premises, namely (a) that "psychophysics" is understood as a matching of stimuli with sensations (rather than, for example, discriminatory behavior), and (b) that sensations are accessible and reportable by the subject who has them (thanks to Trey Boone for prompting me to clarify this).
} 
disagreed about basic methodological questions in a way that directly corresponded with their respective conceptions of the aims of a psychology of perception.

\section{Phenomenological and Non-Phenomenological Methods}

In the literature it is sometimes suggested that specifically "phenomenological" methods in have an important place in contemporary perception research (Hatfield 2005). This invites the question whether there are also non-phenomenological methods and how the difference is to be characterized. Some insights can be gained by contrasting the phenomenological approach championed by the Gestalt psychologists in early $20^{\text {th }}$-century research on perception, contrasting it with the methods of their atomistic rivals in the Wundtian tradition. I will argue that both methods aim at eliciting reports about phenomenal experience, and both can be considered psychophysical. Where they differed was in their conceptions of the aims of perceptual research, and this had a direct impact on the kinds of experiments they conducted.

\subsection{Gestalt Psychology and the Phenomenological Method}

To get a sense of what constitutes a "phenomenological" method, it is instructive to turn to one of the classical experiments conducted by Wertheimer in 1910 (see Wertheimer 1912). His research was informed by the recognition that when we see two separate stimuli in short succession, we perceive the first stimulus as moving towards the location of the second, and he aimed at determining the precise conditions under which this phenomenon occurred. Wertheimer's methodology consisted in (a) carefully varying the experimental setup (the time interval, the spatial separation, the form of the stimulus, etc.), and (b) paying close attention to the resulting phenomenal experience. In a nutshell, Wertheimer found that when the time interval is long (200 milliseconds), the two lights are perceived as alternating, when it is very short (30 milliseconds), they are perceived as flashing simultaneously. However, in between (60 milliseconds or slightly less), the observer either perceives a moving light flash, or simply a movement. This perception of pure movement is what Wertheimer referred to as the "phi-phenomenon."

What makes this method "phenomenological"? I suggest three answers. First, subjects" descriptions like "I see pure movement" are given a fundamental authority. In other words, there is no conceptual space for the possibility that subjects might be deceived about what they are 'really' experiencing. Second, and relatedly, the research aims to find out which constellations of stimuli gives rise to which kinds of experiences in subjects. Third, the experiments are exploratory in the sense that they vary stimuli in order to determine the physical conditions that give rise to the appearance in question. In other words, the research is descriptive. Hatfield (2005) has singled out the second feature of Gestalt-psychological experiments as "introspective." While I think that the terminology of introspection my well end up having a legitimate place, I prefer the terminology of first-person reports at this points, in part because it seems counter-intuitive to describe subjects' reports as introspective when they are describing something that they perceive as being located in the outside world.

The very rigorous set-up of the types of experiments championed by Wertheimer and his colleagues presents some arguments against worries about the potentially arbitrary nature of firstperson reports, which arise from the fact that we don't have very stable intuitions about what we are 'really' experiencing. For example, Schwitzgebel (2011) argues that it is not clear whether my phenomenal experience of a coin is determined by what I know about it (that it is round) or whether it is determined by what I see when taking a painterly attitude (elliptical). In response Hatfield (2005) points to empirical research that suggests that such ambiguities can be reduced if subjects are properly instructed: It has to be made clear to them that they are expected to report 
neither the objective shape (what they know the shape of the object to be) nor the projective shape (what they know the projection on their retina to be). Once this has been done, Hatfield argues, one can get fairly robust results about shape constancy. This is precisely what the example of the phi-phenomenon illustrates, since Wertheimer's experimental set-up aimed at (and succeeded in) eliciting robust responses. On the other hand, however, one might worry that the experimental stability comes at a cost, namely that the experimental instructions are specifically designed to produce data that fit with the experimenter's expectations. We will return to this issue below.

\subsection{A Non-Phenomenological Approach to Phenomenal Experience}

I argue that the phenomenological approach outlined above qualifies as 'psychophysical.' This is also backed by Wertheimer's own assessment (see Feest forthcoming). Having outlined the aims and methods of a phenomenologically oriented approach to psychophysics, what might a rival non-phenomenological approach look like? And what rationale is there for saying that such a non-phenomenal approach is also one that prompts phenomenal experience and elicits selfreports of such experiences?

Historically, prominent advocates of a non-phenomenological approach to phenomenal experience were members of the Wundtian school of sensory psychology. They saw their task as that of identifying the basic atoms of experience, and they sought to identify those by presenting subjects with isolated stimuli, designed to create 'isolated' basic sensations. While Wundtians were aware of the fact that we don't experience such basic sensations, they believed that the more complex sensations we do have can be decomposed into basic ones, even if we are not consciously aware of them under normal perceptual circumstances. The point of their experiments, then, was to make these basic sensations accessible to conscious awareness. Wundtian atomists were convinced that the project of explaining complex experiential states would ultimately have to make recourse to such elements. By contrast, Gestalt psychologists emphasized the primacy of holistic perception (for example the perception of movement as a function of a constellation of stimuli), and held that even when it seems possible to analyze a complex experience into parts, these are after-the-fact abstractions and do not represent the constituents of holistic experiences, and hence that no psychological explanations of the kind envisioned by Wundtians were to be had.

I argue that if a subject is asked to report their experience of a given atomistic external stimulus (or the relationship between two stimuli), and they answer (for example), "bright" or "red," or "equally bright," there is a perfectly legitimate sense in which they are reporting a phenomenal experience. In this sense, then, I suggest that the atomistic approach, like the holistic approach of the Gestalt psychologists, elicits reports about phenomenal experience. The difference between the two, I suggest, is that they differed (a) in what they conceives to be the purpose of gathering such reports, and (b) consequently they differed in the kinds of experimental stimuli and instructions they present to their subjects: Whereas the phenomenologically oriented Gestalt psychologists wanted to determine the empirical conditions under which first-person reports of particular experiences can be elicited, the non-phenomenologically oriented atomistic psychologist sought to identify the basic constituents of human perception, which they thought to correspond to basic stimuli. This accounts for the different kinds of experiments they each designed. ${ }^{2}$ However, while the rationales for their experiments differed, I would argue that there

\footnotetext{
${ }^{2}$ It seems to me that Mazviita Chirimuuta, in her contribution to this panel, is getting at a related idea with her distinction between minimally introspective and introspection-heavy methods (the introspection-heavy being the one I refer to as "phenomenological").
} 
was nothing as such wrong with the first-person reports generated by either of them. Rather, the epistemologically more interesting feature of their respective empirical data was the extent to which they were the outcomes of very carefully designed experiments.

\section{The Artificial and the Artifactual}

In the previous section I have drawn attention to the fact that different schools in the psychology of perception design very different kinds of experiments to elicit first-person reports about phenomenal experience. Both the stimulus material and the instructions are designed to (and did) produce robust empirical results. Robustness of first-person reports is no guarantee for veridicality. Still, I believe that the discussion shifts our attention away from issues of veridicality, highlighting instead the question of how to adjudicate competing robust experimental results that are both based on first-person reports.

The case studies direct our attention to the role of the experimenter and the extent to which first-person data (like other experimental data) are constructed and artificial. They result from specific arrangements of stimuli and experimental instructions. The art of experimenting is exhibited to a significant extent in the ability to create robust results. This is achieved by presenting 'the right kinds' of stimuli, and making the experimental instructions as unambiguous as possible, such that all subjects do roughly the same thing in response to the stimuli presented to them. Now we can return to the question already raised above, namely whether the artificiality of the experimental set up and the constructedness of the experimental data further or undermine their purpose of contributing to our understanding of perception? I suggest that in addressing this question we need to distinguish between (a) the fact that experimental set-ups are artificial and (b) the question of whether the experimental results are artifacts.

The worry that scientific experiments in perception research create phenomena not ordinarily found outside the laboratory was explicitly addressed by Kurt Koffka (1923), who argued that all experiments about perception create perceptual experiences that differ from the ones subjects might have (even of the same stimuli) if they were not participating in an experiment. For Koffka, this was a simple consequence of the fact that the subjects of an experiment are instructed to do certain things, which creates a mental "set" [Einstellung]:

"Every psychological description ... presupposes a set, which is different from that of normal life, where we are directed towards entirely different goals than that of description. Hence, every description will find phenomena that are novel vis-à-vis ordinary phenomena; phenomena that are changed in some way or other" (Koffka 1934, 383; my translation). ${ }^{3}$

Koffka did not view this as an objection to the experimental study of perception, arguing that such experiments aim at substituting ordinary experiences with experiences that are illuminating with respect to perception. The job of the experimenter, according to him, was to ensure that subjects are in the right kind of "set." In other words, Koffka fully acknowledged the active role of the experimenter in creating specific types of first-person reports. In this respect, Gestalt psychologists and atomists were obviously on a par; they played equally active roles in creating experimental conditions that gave rise to experiences that they deemed to be illuminating with

\footnotetext{
3 "Jede psychologische Deskription - wie jede Deskription überhaupt - setzt bereits eine Einstellung voraus, die verschieden ist von der Einstellung des gewöhnlichen Lebens, in dem wir auf ganz andere Ziele gerichtet sind als auf Beschreibung. Jede Deskription wird also notwendig Phänomene vorfinden, die neu sind gegenüber gewöhnlichen Phänomenen, die, in welcher Weise immer ... verändert sind.“
} 
respect to perception. Yet they disagreed with each other both over the value of their respective experimental set-ups and about the results they purported to find.

One way to construe the disagreement is to say that while both acknowledged that they were actively constructing specific first-person reports, they each accused each other of drawing faulty conclusions, resulting in 'findings' that were essentially artifacts of faulty background assumptions about the aims of psychology and the nature of the mind, and they held that the other party's faulty background assumptions were already built into the very experiments they conducted. More specifically, atomists charged that the fact that we don't perceive elements of sensation under normal conditions does not mean that there are no such elements, and Gestalt psychologists charged that the fact that such elements can (seemingly) be isolated under specific experimental conditions does not mean that they play any role in normal perception.

\section{The Problem with First-Person Reports as Arbiters, and a Proposed Solution}

As we saw, the disagreement just outlined was neither about the robustness nor about the veridicality of the first-person reports generated by either party. Rather, it was about whether those results were relevant to the task of "saying something illuminating about perception," i.e., whether they established what each party claimed, i.e., (in the case of atomists) that perception can be decomposed into elementary sensations, and (in the case of Gestaltists) that the most basic and immediate experiences are structured in ways that correspond to certain stimulus configurations. In this final section, I will argue that this disagreement was not resolvable by appeal to the empirical data (i.e., the first-person reports). In response to the question of how the disagreement could possibly be resolved, I will suggest that we turn to broader methodological considerations. Again, the historical case gives us some intriguing insights.

\subsection{Problems with First-Person Reports as Arbiters}

Rhetorically, Gestalt psychologists often appealed to the external validity and the face validity of their findings, emphasizing (a) that their experimental data clearly resembled ordinary experience much more closely than those of Wundtian atomists, and (b) that their empirical findings simply showed them to be right, because (for example) the subjects in Wertheimer's phi-experiment did not report experiencing simple elements of sensation. However, as we just saw, they were well aware that things weren't that easy. There are two reasons for this. The first was the one already discussed, namely that they recognized that the mere artificiality of the Wundtian data did not discredit them from being genuine scientific data, and that in fact their own data were artificial, too. The second reason was that they realized that the first-person reports themselves could not decide for or against atomism either way. The fact that atoms of experience are not normally experienced, except under the special conditions of a Wundtian experiment, could not be appealed to as evidence against Wundt, because he did not claim that these elemental experiences were accessible under normal conditions. This is precisely why he sought to isolate them in special experiments. In this vein Wundt argued that we also do not perceive physical atoms, and yet they are useful and valid explanatory constructs in physics (Wundt 1907).

The fact that this conflict did not seem to have a straightforward empirical resolution, had been recognized by the Gestalt psychologist, Wolfgang Köhler already some 10 years earlier, when he stated that "the refutation [of the view that there are unnoticed sensations and judgments] by observation and experimentation ... must be considered hopeless, since it is precisely one of the basic assumptions of this view that there is unnoticed, even unnoticeable, psychological content, and thus, it can be seen, the relevance of observation is excluded once and for all” (Köhler (1971 [1913]), 18). He thereby wished to make it clear that the Wundtian 
approach should be treated with some respect as a rival scientific hypothesis rather than simply an article of faith. Having established that they were both reasonable scientific hypotheses and that they could not be adjudicated by appeal to first person reports, he proceeded to ask what other kinds of criteria one might possibly appeal to when trying to decide between them.

\section{$\underline{5.2 \text { Köhler and the Appeal to Epistemic Virtues }}$}

In Köhler's article "On Unnoticed Sensations and Errors of Judgment," he criticized atomistic reasoning strategies not because their assumptions didn't conform with 'normal' experience, but because they were too easy to come by. Specifically, he argued that (a) in cases where first person reports of experiences did not reveal elements of sensation, it was too easy to say that those sensations were there but were "unnoticed," whereas (b) in cases where first person reports did not match what one would have predicted on the basis of the presumed elements of sensation (for example, in the case of optical illusions), it was too easy to say that the sensations had been distorted by an unnoticed error of judgment. He concluded:

"Enough of this. These two auxiliary assumptions ... are shown to be ... general and incapable of being disproved in most individual cases. This is the first reason why these assumptions do not recommend themselves from a scientific and technical point of view. ... It has been shown, in the second case, that no independent criteria exist in specific cases to decide ... when we must have recourse to these assumptions and when we must, rather, accept an observation as an exception to the basic assumption. Thus the door is opened to arbitrariness.' (Köhler 1913, 27/18).

Essentially, then, Köhler appealed not to first-person reports to settle the disagreement, but rather to a specific understanding of scientific method. According to this understanding, auxiliary assumptions are permissible in scientific research only insofar as there are criteria that restrict the ways in which one can appeal to them. On his analysis, the problem with the atomistic hypothesis was neither that its experiments used first-person reports, nor that those reports contradicted those gathered by Gestalt psychologists. Rather, it was that that too many ad hoc hypotheses were required to reconcile it with specific experimental findings. It would go beyond the scope of this paper to evaluate this line of argumentation in detail; however it is worth noting that it corresponds to something like the Kuhnian notion of epistemic values as guiding the choice of hypotheses (Kuhn 1972), and to the more recent literature about epistemic virtues of theories (see Tulodziecki 2012 for an overview). In this vein, it seems to me to be a fruitful avenue for future research to examine the ways in which different ways of constructing first-person reports are (or should be) be evaluated within the science of perception.

\section{Conclusion}

In this paper I have argued that while much of the debate about the value of first-person reports in psychology turns on their status as "scientific" and on their veridicality, philosophers of science until now have not paid much attention to the extent to which first person reports (like other kinds of data) are highly artificial and carefully constructed by experimental means, often with an eye to specific research projects. This has prompted me to raise an epistemological question stemming from the fact that that even psychologists of perception who agree on the value of firstperson data can disagree deeply about what the data reveal about human perception. The reason for this, I suggested, is, that even where scientists have no reason to doubt each other's data, they may still have fundamental differences over the value of the very experimental set-ups that went into their production, and hence over the inferences one can legitimately draw from the data. I 
illustrated this point by recounting a discussion that took place in the early $20^{\text {th }}$ century between atomistic and holistic approaches to the psychology of perception. Both, I argued, constructed their experiments with specific background assumption in mind. I showed that ultimately their disagreement was not about the first-person reports as such, and that moreover the first-person reports could not settle their differences, thus drawing attention to the question of what other criteria one might turn to.

An obvious response to the argument of this paper is to ask about the status of the historical case study, thus raising the question of whether this case is representative of epistemological issues that arise in connection to more recent research as well. I would argue that the historical case brings out the issues in a particularly clear way, in part because the historical actors explicitly reflected on them in their methodological writings. However, the relevance of these reflections goes beyond the narrow confines of this particular case, since they arise from the recognition of the high degree of craftsmanship of experimental research, and to the constructedness and artificiality of experimental data (including first-person reports) in the science of perception. The constructedness of first-person reports in the experimental investigation of perception does not invalidate them per se, but it does raise questions about the inferences they license about the nature of perception. More specifically, it raises questions about the criteria that should determine our judgment of whether or not a given experimental result is illuminating with respect to perception. ${ }^{4}$

\section{REFERENCES}

Brentano, Franz C., 1973. Psychology From an Empirical Standpoint. London: Routledge. (First published 1874 in German: Psychologie vom empirischen Standpunkt)

Bühler, K., 1907, “Tatsachen und Probleme zu einer Psychologie der Denkvorgänge I. Über Gedanken." Archiv für die gesamte Psychologie IX(4), 297-365.

Feest, Uljana, 2012. "Introspection as a Method and Introspection as a Feature of Consciousness.” Inquiry 55(1), 1-16.

Feest, Uljana, "Quantifying Gestalt Qualities: Modernism and the Measurement of Experience." In M. Epple \& F. Müller, (Eds.), Modernism in the Sciences. Berlin: Akademie-Verlag (forthcoming)

Hatfield, Gary, 2005. "Introspective evidence in psychology." In P. Achinstein (Ed.), Scientific Evidence. Philosophical Theories \& Applications. Baltimore and London: Johns Hopkins University Press, 259-286.

Köhler, Wolfgang, (1971 [1913]), “On Unnoticed Sensations and Errors of Judgment.” In Mary Henle (Ed.), The Selected Papers of Wolfgang Köhler. New York: Liveright, pp. 13-39.

Koffka, Kurt, 1923, "Zu Theorie der Erlebniswahrnehmungen," Annalen der Philosophie III, 375-399.

Kuhn, Thomas, 1977, "Objectivity, Value Judgment, and Theory Choice." In The Essential Tension. Chicago: University of Chicago Press, 320-339.

Overgaard, M. and Sorensen, T. A., 2004, "Introspection distinct from first-order experience." Journal of Consciousness Studies, 11(7-8), 77-95.

Piccinini, Gualtiero, 2009, "First-Person Data, Publicity \& Self-Measurement." Philosophers Imprint 9(9), 1-16

Robbins, Philip, 2006, “The Ins and Outs of Introspection.” Philosophy Compass 1, 617-630.

\footnotetext{
${ }^{4}$ I would like to thank the audience at the Center for Integrative Neuroscience in Tübingen (May 2012) and Mazviita Chirimuuta for helpful feedback on an earlier version of this paper.
} 
Schooler, Jonathan, 2002, "Re-representing consciousness: dissociations between experience and metaconsciousness." Trends in Cognitive Science 6(8), 339-344.

Tulodziecki, Dana, 2012, "Epistemic Virtues and the Success of Science." In A. Fairweather (Ed.) Virtue Scientia: Bridges between Philosophy of Science and Virtue Epistemology, Synthese Library, Springer (forthcoming)

Wertheimer, Max, 1912, “Über das Sehen von Bewegungen." Zeitschrift für Psychologie und Physiologie der Sinnesorgane, Vol 61, 161-265.

Wundt, Wilhelm, 1907, "Über Ausfrageexperiments und über die Methoden der Psychologie des Denkens." Psychologische Studien 3, 301-60 